\title{
Dawacom Human Resource Management Reality and Ambition
}

\author{
Nasser Assaf ${ }^{1}$, Saleh Alhusan ${ }^{1}$, Ahmed El-Qasem ${ }^{1}$, Mohammad Al Qudah ${ }^{1}$ \& Abdelkareem Alzou'bi ${ }^{1}$ \\ ${ }^{1}$ Business Administration Department University of Petra, Amman, Jordan \\ Correspondence: Nasser Assaf, Department of Business Administration, University of Petra, Amman, Jordan. \\ E-mail: nabali1983@gmail.com or nassaf@uop.edu.jo
}

Received: January 2, 2017

doi:10.5539/ijbm.v12n3p62
Accepted: January 15, 2017 Online Published: February 22, 2017

URL: https://doi.org/10.5539/ijbm.v12n3p62

\begin{abstract}
This project explores the human resource management (HRM) that's the organization needs in order to perform effectively and efficiently. Dawacom HRM is the case study of this project, using qualitative approach methodology, and collecting data via researcher observations, experiences, and practices.

Through the project we expect to identify Dawacom HRM roles, tasks, objectives, workflow, and manager's duties. Also, this project explores Dawacom HRM attributes, diversity, job analysis, recruiting and selecting processes, compensation systems, measuring HRM performance, training and developing programs.

The project highlighted issues that affect HRM Processes and organization performance such as: health and safety, ethical workplace and fair treatment, global human resource.

The project will show Dawacom HRM advantages and disadvantages and how can improve Dawacom HRM by what actions, personnel, cultural things. So, HR team will be able to focus his importance toward those areas.
\end{abstract}

Keywords: human resource management (hrm), dawacom, recruiting, compensation, job analysis, organizational performance

\section{Introduction}

In the middle of 2009 was established. A small, ambitious pharmaceutical company. Al- khomasyia Pharmacy Company was named. It was had 3 branches with small store $\&$ office at the helm of one of those branches. It had a few capital with a lot of challenges and obstacles, but have a plenty of insistence and resoluteness.

At that time, 2500 Retail pharmacies was already registered in Jordan, in addition to those also 2 of chain pharmacy companies, was started few years before. Add to that, 2009 was the time of the storm of the global financial crisis, causing it to lack of investment flows, reservation bales for funding.

Although all of the above, working started, and many of the biggest global company was declined to invest and found a chain pharmacy in Jordan, which helps the new company Al- khomasyia to still \& expand. Because of small capital \& low of cash flow, the company choose strategy to invest in employee \& goods to raise her sales and creates a niche in the pharmacy market share. Choosing low running cost, good but stumbled, already existing pharmacy to acquisite instead of founding new retail in modern area which needs a lot of money \& investments.

Implementing these strategy strictly, the company could only in 2years after, reach 17 branch with a a huge Store, and her main dependent offices. At that time the company by her board of Directors decided to review, and reformulate her mission, objective, goals even her vision.

In the late 2011, board of directors gathered in retreat, then they designed and reshaped the new mission, vision, objectives \& goals and the most important thing was to go to is Branding.

Dawacom was the new name or the brand of Al-khomasyia Company, the name that will not be used thereafter, also these retreat include transforming the business from company stage to corporation stage. Dawacom Corporation formed from 4chain pharmacy companies (4 company with 100 branches in 5 states), Kalemat drug store (July 2011, about 10 agencies), Dawacom general trading company (May 2013, import medical devises \& equipment's baby supplies, beauty Accessories). Dawa academy training center (June 2013), medicines plant " not yet" finally hospital. Although all of the above chain pharmacies is the core businesses other companies supported it. 
Health care center was the concept designed by the marketing department of Dawacom after many researches \& market studies, this is a new concept in pharmacies' market in Jordan. Pharm mall, traditional pharmacy were the only concepts in Jordan pharmacies' market. This concept needs new structure solutions.

Providing patient counselling in healthy, comfortable. Clean atmosphere is the corner store of building customer relationship which make money \& profit \& sustainability to business. Also the quality \& productivity of the Assets - especially human capital- playing major role in the effectiveness of business units.

At the beginning of 2013 restructuring, redesigning, branding \& decorating processes was started to implement now concept \&strategy. Beside those branding processes, an internal administrative structure was reshaped, department redesigned to fits new organizational direction \& objectives. In addition to technical, sales, marketing, operating, finical departments, HR, support services and maintenance department were need to visualize deeper.

More than 500 employee, 100 retail, 10000 customers- in average-, All those operations and stakeholders require tight, well organized system to ensure effectiveness \& efficiency and maintain productivity.

\section{Preliminary}

Human resource management (HRM) is the management of human resources. It is a function in the organizations designed to maximize personnel performance to serve an employer's strategic goals. (Johnason, 2009).HRM is primarily concerned with the management of employees within organizations, focusing on systems and on policies.(Collings, \& Wood, 2009).

HR in Dawacom considered as a critical \& main part in managing the organization. Pharmacists and Other health care professionals are the backbone of Dawacom business, so HRM policies \& practices influence directly on the performance of the organization \& employees. HRM starts before attracting C.Vs, and not ending at shaping a comfortable, family-like environment workplace.

Edward L. Gubman (1996.) observed in the Journal of Business Strategy, "The basic mission of human resources will always be to acquire, develop, and retain talent; align the workforce with the business; and be an excellent contributor to the business. Those three challenges will never change".

So, HRM involved in recruiting, selecting, interviewing new employees \& training them, appraising \& rewarding employees, in addition to that HRM enrolled in all employees affairs such as payroll, compensations , incentives, leaves, vacations, administration letters, employee profile and So On.

Behind these jobs HRM playing a cornerstone roll in planning \& developing personnel jobs, organizing teams \& creating healthy comfortable, family environment work place also spreading motivation, quality value commitment to organization goals \& culture.

According to Mondy et al. (2014), human resource management HRM has many core functions which are:

- $\quad$ Staffing

- $\quad$ Training and human resource development

- $\quad$ Compensation system and benefits

- Health and safety

- $\quad$ Employee and labor relations

A Human Resources Manager has several tasks in an organization:

- $\quad$ Forecast needs of the staff.

- $\quad$ To fill these positions, determine to use temporary staff or hire employees.

- $\quad$ Select and train the best employees.

- $\quad$ Supervise the work.

- Harmonize relationship between firm and employees.

- $\quad$ Manage worker relations.

- $\quad$ Prepare the employee records and personnel policies.

- $\quad$ Manage worker payroll, compensation, \& benefits.

- $\quad$ Assure equal opportunities.

- $\quad$ Protect employees from discrimination. 
- $\quad$ Insure performance issues.

- Guarantee that HRM practices conform to regulations.

- $\quad$ Boost the employee's motivation. (Mondy, 2014)

Managers has to develop their skills to be effective. Organizations behavior focuses on how to improve issues that trigger organizations to be more effective. Effective HRM enables employees to contribute effectively and productively to the overall company direction and the accomplishment of the organization's goals and objectives. (Susan, 2016)

In Dawacom HRM systems we can clearly obtain 4 main objectives:

1. Developing loyal, highly committed. well trained skillful, qualified fully motivated, ambitious staff in a family environment, quality valued culture with best compensation systems.

2. Investing in our staff $\&$ achieving job satisfaction.

3. Providing the most effective training programs by the latest tech. to the best selected staff.

4. Enhancing working as a team according to our values, continuing to develop \& quality our staff to provide distinguished services to maintain our good reputation to achieve our goals.

All these HRM lines \& objectives work parallel to achieve Dawacom goals. Helping in performing these activities, our unique ERP (Enterprise Resource Planning) " Durra " system, which automate all HR operations and shortens the times of doing them efficiently \& effectively.

\subsection{The current HRM of Dawacom}

Dawacom HRM features effectiveness, spirited, and dynamics, because it is using a fully automated ERP "Durra "system, performing cleared jobs \& workflow steps by HR team. In addition to documented, announced, yearly revised By law and code of ethics which control all employees behaviors in the firm. All HRM procedures \& policies goes with national laws and never exceed it. Dawacom HRM designed a unified payroll, position upgrades system, boosts fairness and ambition.

Dawacom HRM and in order to achieve job satisfaction \& fairness, performs a detailed job description for each employee with KPIs (Key Performance Indicators) to do appraising based on it. A written job definition and description are the keys to achieve job expectations to people (Meir Liraz).

Dealing with the employees as a customer is a critical issue to HR team. The more accurate and realistic the specifications of and skill requirements for each job, the more likely it is that workers will be matched to the right job and, therefore, be more competent in that job.

Despite all of the above, Dawacom HRM faces many challenges that need to overcome in order to get a decent position internally and externally.

Little, shallow experience of HR team relative to complicated, huge operations, decrease the efficiency and slows down work procedures and delay the responding to management \& employee requirements, in addition to insuring books and circulars. HR is expected to sit at the executive table and recommend processes, business solutions, and approaches, that improve the ability of the organization's workers to effectively contribute.( Susan M. , 2016).

Adding to all the above, there is poor qualified candidates in the recruiting pool especially for excusive positions. Losing control policy in following employees' official working attendance, leaving and vacations which make troubles for the supervisors. So that Dawacom HRM needs multiple solutions to overcome these problems.

\section{Theoretical Basis}

\subsection{The Job Analysis}

The success of every company is dependent upon the performance of its workers. Ideally, all of the tasks in an organization should interrelate to maximize the accomplishment of the organization's mission, objectives and goals. The return on investment will be influenced to a large extent by how well personnel understand their role in the organization. As a result, job analysis is considered by many HR professionals to be a vital aspect of effective human resources management. It has the potential to affect every major core competency issue of HR, for better or for worse, depending on the efficiency of the underlying job analysis practices within the firm. For example, although the type of information needed by each HR practice unit may vary, job analysis information can and are used to determine the skills, knowledge, and experience required to effectively perform job tasks, found criteria for selection and promotions, design plans for training and development programs, obtain the standards for the measurement of performance, and/or estimate compensation level (Sagar, 2014). 
Job analysis is a collection of procedures to recognize the content of a job in form of activities encompassed and job requirements or attributes needed to perform the activities. Job analysis provides data to companies which aids to decide which employees are best fit for certain jobs. Through job analysis, the HR specialist needs to determine what the essential tasks of the job are, how they are executed, and the important human qualities needed to do the job successfully. The process of job analysis includes the HR specialist describing the tasks of the employee, then the conditions and nature of job, and finally some primary specifications (Wilson, 2007).

As we see, job analysis considered one of the essential tasks of the HRM, it lays on the middle line of the HRM. Job analysis includes determining the career requirement positions to be filled, skills and qualifications needed for each position, detailed job description, communication channels up and down, training requirements and job specifications for the position.

One of the main causes of performing job analysis is to prepare job descriptions and job specifications which assists hire the right kind of workforce into the company. The general object of job analysis is to document the requirements of the job performed. Job and task analysis is executed as a basis for later enhancements, including: determining of job domain; description of a job; personnel selection systems, performance appraisals, training needs assessment, compensation criteria, and promotion plans ( Robinson, 2012.).

Via job analysis we can gather data that form a clear picture about particular job. These information include in addition to work activities, human behaviors, performance standards (KPIs), job context, human requirements , machines, tools, equipment, and work aids (Gray,2012).

Section A and section B at the appendix show us two examples of job analysis used by Dawacom HRM, one of them for junior position, the other for supervisory position.

\subsection{The Testing, Selection \& Interviewing Process}

A business is only as good as the personnel in it. Therefore, to effectively manage your business, you should take the time to find and hire the right staff. Staffing is sensitive to businesses of all shapes and sizes. All companies in hiring a new employee take the same risk. However, smaller companies, is less able to afford the time and costs related to hiring and then firing, the wrong person. Companies have developed efficacious hiring processes and procedures to decrease this risk. Dawacom HR manager is going to effectively manage this operation, he must apply most of these staffing techniques.

The process of staffing a business includes: establishing the personnel policies, setting skills and capabilities are needed, attracting applicants, designing application forms, and interviewing possible employees (Meir Liraz).

So, the correct choose of an employee save time and money, and results in performing tasks in proper way to achieving organizational goals \& retaining profits. So don't disparage this issue and always give this task focused importance, thus this is the tool to supplement the firm with competencies \& capabilities.

Dawacom HRM based on a theory characterized that the employee is the edge of our competitiveness in dealing with our customers and serving them. So we design special tools to perform a correct choosing way for those needed employee that they formed our valuable asset.

The screening process presents information about applicant skills, attitudes and knowledge, enabling an employer to decide whether that one is suited to, and qualified for, the vacancy. Experience has noted that hiring an overqualified person can be problematic as hiring an under qualified employee. The application form is the object to begin screening candidates for a job. It

give us information on the applicant's background and training and enables us to compare the applicant with the job description. This will ensure that we don't spend time on applicants who clearly do not meet the minimum specifications for the job.

Generally, on an employment application form the following information is requested: name, address, education, vacancy desired, work experience, military service, telephone number, and references. (Meir Liraz)

At the beginning of screening process, recruiting specialist contacts different foundations to attract candidates and making a pool of applications. Calling Universities, Professional associations, recruiting agencies to collect candidates. In addition to that, effective online and newsletter ads to motivate candidates to submit application via our website. More than 8000 application now we have in our candidates' pool.

The personal interview is the second step in the screening process. During the interview, the manager learns more about the applicant through face-to-face contact, including observation of personal appearance. The interview should be guided, but not dominated, by the manager as it is important to let the candidate speak freely. 
Whenever possible, the interviewer should ask questions that are directly related to the job. Devise a list of questions that will adequately assess the applicant's qualifications while meeting the specifications for the job.

When a position become vacant, recruitment specialist goes to the ERP system that linked to our website and fill the job description and specifications related to that vacancy, so the ERP automatically filter the applicants linked to that job analysis, then he collects those related applicants and contact them to attend to the firm to perform a screening exam that includes (English, math, IQ , technical tests). After that exam and depending on the vacancy specifications, recruitment specialist chooses the best 5 ( or more or less it depends ) results and inviting them to a detailed interview .

The first interview conducted by a committee which includes: HR specialist, technical specialist (related to the position), manager or supervisor of the vacancy. This committee assess the applicant through structured \& unstructured questions, play rolls, designing a project, stress conditions and so on. Thus, they discover the knowledge, skills, experience, behavior, perception, personality of the applicant. Each member of the committee write his notes, then the committee take final decision. (See section $\mathrm{C}$ in the appendix :interview form)

HR manager selects the best 2 results from the committee interview and invite them to a final interview with HR director \& VP. This final interview is general screening, unstructured. It aims to ensure that the impressions \& decisions of the committee were true, and to explore the organizational realization and motivational issues toward the firm in the selected applicant. Based on the final interview, the HR director \& VP select one of them and introduce an offer for him.

Generally, the test and interviews done in different 3 days to ensure impressions about the applicant, and to give him a chance to exclude any circumstances that may related to a situation in one day. Also generally, the test takes 1 hour, the committee interview takes 1 hour, and the final interview takes 30 - 40 minutes. More time, more tools (such as seminar, projects ... etc.) may be inquired to supervision $\&$ executive positions.

\subsection{Diversity}

The god created us in various forms, from variant origins, cultures, colors, genders to nourish the life and to mix cultures, so increasing the experience enrichment, and broaden the knowledge base. Diversity can be showed as a multi origin workforce, equal opportunities to be in, for different gender, colors, religions, as well as age groups \& disable groups .

Workforce diversity recognizes the reality that people varied in many ways, visible or invisible, mainly gender, marital status, age, social status, sexual orientation, disability, religion, ethnicity, personality, and culture (kossek et al., 2005). Mcleod, Lobel and Cox (1996) and Wilson and Iles (1999) found that " a diverse workforce has a better-quality solution to brainstorming tasks, displays more cooperative behavior, relative to homogenous groups, and can raise organizational efficiency, effectiveness and profitability. in addition to the full utilization of the skills and potential of all employees, managing diversity effectively can contribute to organizational success by enabling access to a changing marketplace by mirroring increasing diverse markets", and improving brand image (kandola, 1995). Therefore, esteeming diversity may become a provenance of competitive advantage, ultimate the quality of organizational life and eventually be good for business (Cassell, 1996).

Diversity management has a place in HRM and should be at the heart of human resource practices and policies. In workplace the issue is not to equalize them in recruiting \& selecting \& interviewing, but exceeds that to includes equal opportunities in career upgrades, to have as executive positions, payroll systems \& compensations, not ending by stop discrimination, depending on this diversity in appraising and dealing with employee actions. Effective HR strategies focus on increasing organizational knowledge creation, learning, flexibility, and the empowering of a work environment which is conducive to diversity management (Jie Shena, 2009).

As the diversity gives the organization with deferent and important various competencies \& experiences that reached because this diversity, also it protects the community and firm fairness and ensuring dealing with the employees as a human and appraising them upon theirs performance and creativity rather than things they not control them. There is a wide recognition of the magnitude of workforce diversity, research by the Australian Centre for International Business (ACIB) indicates that diversity promote the goodness of management's decisions, and supplement innovative ideas and better solutions to organizational troubles (ACIB, 2000). Especially in multinational organization, diversity plays an important role in facilitating district markets penetration, that the diverse workforce gives us the attributes of that market in less cost research with the help of those employees.

A conceptual framework of HR diversity management is suggested and shown in figure 1. This model indicates that diversity management includes Equal Employment Opportunity EEO/ Affirmative Action AA as well as 
valuing and applying diversity. Diversity management should rely at the strategic, and operational levels through a multi different activities embracing managers at all levels. The below model also highlights the ultimate goals of diversity management. These goals include advantages to organizations and personnel which can generate from good diversity management. (Jie, 2009).

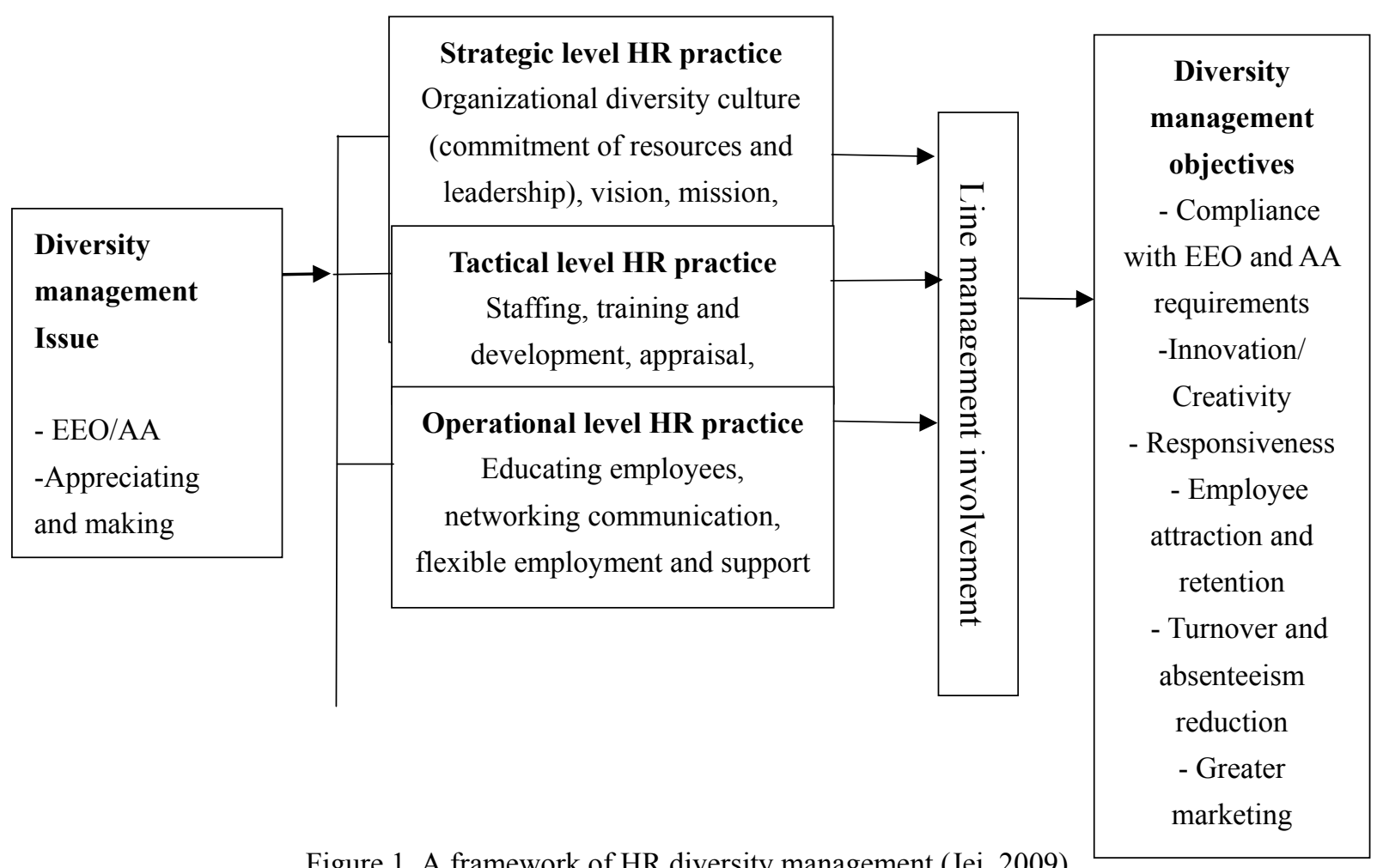

Keywords: Affirmative Action (AA); Equal Employment Opportunity (EEO);

Although of those advantages, many obstacles face the diversity in the organizations, different languages and cultural barriers limit effective communications between workforce employees, also dynamic nature for some jobs limits roles of handicaps or females.

Sometimes customers play a role in the degree of diversity we can have. Depending on customers' needs and satisfaction we limit diversity in the work place that contact with the customers. For example some customers feel more comfortable in dealing with female, Others like to be served by older person and so on . Anyway diversity enriches the workforce when treated upon the capabilities needed by the organization and customer satisfaction.

\subsection{Training and Developing the Employees}

To be successful in this tough environment, an organization employees have to captures a "competitive edge" that distinguishes them from other organizations workers with similar qualifications and comparable outcomes (Schulz, 2008). Therefor, and In order to be a good professional, personnel should possess a combination of comprehensive technical, knowledge, experience, soft skills, and problem-solving (Burke, et al., 2008).

So, and since the beginnings, training and developing employee was essential issue in Dawacom HRM. We believe that the more trained and developed employee, the most benefits and customer serving you will generate. So we design a multi dimension training courses and activities along with the career path.

From day one, the employee starts with training, this first training called "orientation". The orientation is done in two steps, general and specific orientation steps. General orientation is done by HR team and it introduces to the new employee the organization vision, mission, strategy, values, business, division, charts and structure, history. Also, general orientation introduces to the new employees internal policies \& practices, work flow, communication ways, career path, code of ethics. Also primary training courses in customer relation management, time management, team work, and communication skills will be convened. Then the general 
orientation ended by a round in the departments of the firm, with small explanation about each department to finalize a picture about the organization he joined to.

Specific orientation is the second step, here it done by the new employee department, and focusing on detailing his job upon his job specifications. The actions, policies, plans, targets,

work flow of his job will be explained. Followed by a three main technical training courses, then a role play and practical training will the new employee undergo.

The duration of the orientation is depending on the nature of the job and the experience of the new employee. Usually orientation takes between 3-10 days, ended by a small quizzes or full test. After orientation and exceeding probation period, the employee takes his position level and clarifying for him the training courses, appraising points that he must take it in consideration. (See section D at the appendix: appraising form)

According to (Brown, 2002) there are four main causes why training needs assessment is important before starting training:

- To explore specific problem aspects in the organization

- To obtain management support

- To develop information for appraising

- To determine the costs versus benefits of training.

Training needs assessment can also be used to identify the learning and performance needs of personnel, functional units, teams, and whole organization (Gupta, 2011).

Training and developing programs in Dawacom has 3 reasons: -

a. Training and development programs that tailored to some employees to improve some issues that appear in their appraisals.

b. Training and development programs that improves employees' skills, knowledge, technical, behavior which lines with career path \& job position levels.

c. Training and development programs that performed to employees that may have a chance to get a supervision tasks or executive positions.

Based on these reasons Dawacom HRM designs three types of training programs:

1- Technical of scientific training programs which aim to improve the knowledge and experience and update technology used by field he is working on, it could be primary or advanced or specialist programs.

2- Soft skills training programs that seek to develop the employees' skills, behaviors, communications and approaches to meet Dawacom values and reputation and achieve goals.

3- Administrative training programs that introduce to all employees regardless theirs position level. It aims in increasing management skills of their jobs, tasks, workplace ... etc. in additional to that, develop their supervision and management capabilities.

Success in professional programs and practice requires not only advanced technical knowledge and skills but also many of abilities (communication skills, empathy, professionalism, etc.) that may not be easily determined by cognitive measures, i.e. "soft" skills and experiences may appear more explicit the employees' performance (Clavier, 2013).

Training and development programs not include just training courses it extends to workshops, online training, social media posts, brochures, simulation programs, double visits, self-training, performing particular researches and projects, participating them in some meetings.

Dawacom training and developing programs like a journey, we focus on feelings of the development process in the employees to ensure that this operation influences their work and improving it. So, not just HR team performing it, but we have specific division for training which called "Dawa Academy " that attracts specialists in a different training programs and using advanced method in performing it.(see section $\mathrm{E}$ in the appendix : career path training)

\subsection{Ethical Work Place and the Fair Treatment in HRM}

Dawacom HRM has an integrated, comprehensive compensation system, which based on a clear, announced payroll framework and incentive scheme, linked to dedicated tasks and targets that had been lunched previously, and fixed legal wages calculations, with extra general benefits that all employees at all departments regardless 
their levels undergoes it. This clear systematic compensation package, creates an ethical \& fair workplace environment that is very critical to enhance the employees work and performing tasks effectively \& efficiently.

Establishing an ethical workplace is a key matter of operating a successful business. Ethical issues can not only disrupt internal operations, but can also effectively scratch brand image your marketing budget have been spent to create. Unethical actions in the workplace may tend to make the news, though businesses have to keep an eye out for these issues.

Ethical violations erode the solid foundation firms have worked hard to build and drive to more serious problems in the future. However, organizations that can successfully establish ethical workplaces enjoy a plenty of benefits, including:

- Higher employee morale - boast in an ethical workplace generates happier employees, which returns into higher productivity.

- Employee retention - glad employees stay with firms longer, which cuts turnover headaches and staffing costs.

- Public prestige - Ethical organizations attract distinctive and loyal customers, which interprets into more sales and higher profits.

- Smoother operations - Without ethical problems, business can focus on building business; not on spinning public backlash and punishing the guilty (Chad, 2013).

HR has the power to shape the company culture. It often do more, than creating and implementing a company ethics policy. Ongoing and open communication is necessary to maintaining an environment that inculcates ethical behaviors such as justice and fair treatment. After establishing ethical behavioral expectations, a next step is the building of a communication platform, such as focus group congresses that insures a forum for explaining ethical issues exists, and an open-door policy (Jackie, 2016). Dawacom HRM applying these platform practices.

Why treat personnel fairly?

- “They're not employees, they're people" Management guru Peter Drucker

- Avoidance of employee claims

- boosted employee commitment with the organization

- Enhanced jobs satisfaction

- Increased organizational loyalty behaviors

Attributes of fair treatment represent:

- Engagement - involving employees in decision making that affect them by searching for their input and allowing them to disprove the merits of others' thoughts and assumptions

- Explanation - ensuring that personnel involved and affected recognizes why that decisions are made and the reasons that underlies the decisions

- Expectation clarity - making sure personnel know up front by what KPIs they will be evaluated upon and the punishments for failure (Gray, 2005).

Ethical workplace and fair treatment in the HRM and workplace environment influences behaviors, response ways of the employees toward firm's policies, actions, and activities. Loyalty feelings and belonging to the organization impressions that boost the employees' intention \& creativity and motivate them to achieve goals, basically influenced by ethical workplace and fair treatment.

\subsection{Compensations System}

The compensation system of Dawacom HRM consists of salaries \& wages benefits, incentives, contributions. Here in Dawacom our compensation system considered as one of our competitive advantages. (See section F in the appendix: compensation system)

- $\quad$ Salaries \& wages :

This is the main compensation system part, it includes basic salary, transportation allowance, experience allowance, work shifts allowance, housing allowance, which tailored on fixed criteria, each one linked to fixed number of salary or allowances. Also this part shows the calculation base of extra work, holidays work, leaves and vacations.

- Incentives : 
This part called the motivational part, it encourage the employees to perform their tasks and achieve their targets more faithful. Each department has its targets, measurable tasks, performance values linked to specific incentive scheme. They should reach their targets and achieve performance values to get the incentive. We have 4 levels of targets $95-99 \%, 100-104 \%, 104-110 \%,>110 \%$ in each level there is a particulate ascending incentive, it may be fixed no., or percentage or both. Also there is a specific task in each department when completing it, incentive will be given.

- Benefits:

It starts with social security, after passing probation period the employee will be entered to the health insurance with his family. Loyalty card will give to the employees a lot of discounts in large no. of shops, restaurants, hotels, resorts, \& malls. In addition to that preferential stock price is given to the employees.

- Contributions :

Dawacom HRM specify a budget in the compensation system to contribute in helping the employees in special situations: completing their education, loans, Occasions, this thing make difference to the employees in a particular situation.

This compensation system was produced carefully to have an edge in the market, to attract qualified candidates and to return distinguished employees, to decrease turn over and related costs. This system not just deal with employees tasks, also his team, department and whole organizational goals achievement.

\subsection{Employee Safety \& Health}

Workplace Health and Safety (WHS), often assigned to as Occupational Health and Safety (OH\&S) includes the assessment and emigration of risks that may affect the health, safety of those in our workplace. This may involve the health and safety of our consumers, employees, visitors, volunteers, contractors, and suppliers. As a HR manager there are legal requirements that you must conform to insure our workplace meets WHS obligations (Government of Australia, 2016).

Introducing a safe, healthy workplace in the organization entrusted with HRM practices and it's a human duty rather than it has a strategic importance to the firm. Feeling safe and no danger on health enhance the productivity of the employees and increase the effectiveness and quality of his job.

Also safe and healthy work place environment contributes in reducing costs relating to increase insurance and medical issues as well health and safety programs improved the organization reputation and give it a picture as employee of choice. Adding to that highly risk dangerous work places push the organization to pay more compensation rates.

Figure 2: creating a safe work environment (Rumel, 2012)

\section{Creating a Safe Work Environment}

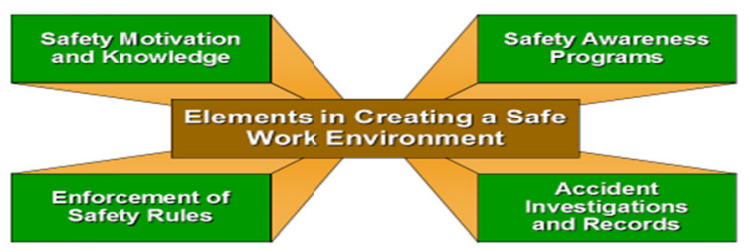

Figure 2. Creating a safe work environment (Rumel, 2012)

Creating a safe work environment is critical to the long term success of our business (Government of Australia, 2016) It can:

- $\quad$ help us retain employees

- maximize staff productivity

- minimize injuries and illness in the workplace

- reduce the costs of injury and employees' compensation 
- $\quad$ ensure you meet legal obligations and worker responsibilities.

The main safe and healthy work place attributes are manifested basically in providing general safety measures in the work place as well providing protection and security measures which is very important and base to create a protection shield to the employee life. Also infection control procedures working on decrease the maintenance measures help keeping the workplaces safe. These attributes seek to prevent accidents diseases, injuries, violence and decrease stress.

In addition to the adore measures, HRM working in increase the employees awareness about safety and security measures, and pushing them through training and activities to stick to those measures as such applying these measures in all Sops (stander operation procedures) of the organization Recording and diagnosing accidents helps the HRM to improve the safety measures and control incidence of new accidents $(\mathrm{CCOH}, 2016)$.

\subsection{Global HRM}

Global human resource management, is an umbrella term that assigns to all HRM aspects on a global scale. It facilitates for organization to perform business across the world. It also refers to the process of recruiting, selecting, developing, appraising, compensating personnel in international or global firms. The firm that manages its operations internationally or overseas.

Global HRM differs from domestic one that every territory has its special different management styles, labor laws, varied payroll practices, different labor markets, as well as other mobility problems such as legal, cultural, political, economic barriers.

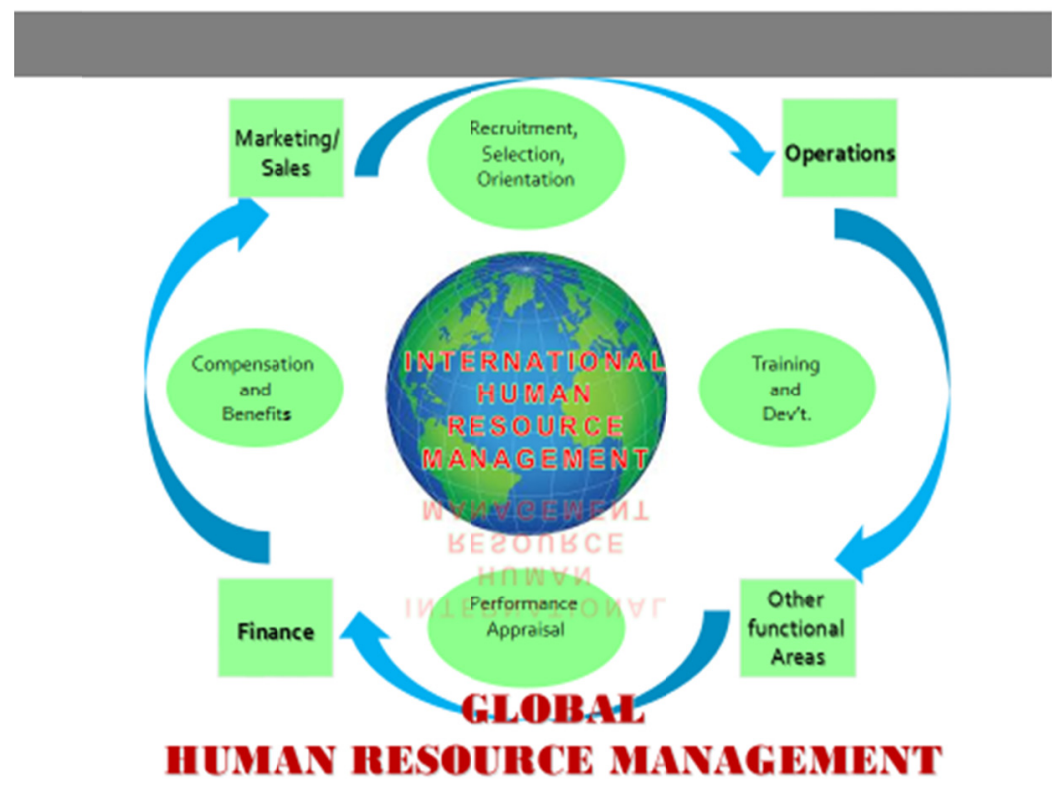

Figure 3. Global human resource management (Malyan, 2014)

Participation of organizations in international business has many ways, it may be importing-exporting with firms in other countries, or multinational which operates branches and business units in other countries, or global organization have corporate units in more than one country are integral to operate globally.

Recruitment and selection processes in global HRM undergo by many approaches to staff many types of global members which includes (expatriates, host country, third country national).

These approaches of global staffing are (Malyan, 2014) :

1. Ethnocentric approach

2. Polycentric approach

3. Region centric approach

4. Geo centric approach 
In Dawacom global HRM we staff expatriates using polycentric approach.

In order to create incorporation between the employees in subsidiaries and host country of the organization, and in addition to primary training and developing system , the global HRM do special preparation program after selecting expatriates employees which include cultural, language ,practical training, these preparation programs give skills in language, culture (of host country and the organization ), local customs, career planning, home country living conditions, expanding skills, life style, workplace employees (signson,2014).

These training and developing and preparation programs implemented by many approaches: one of them is to send the training specialists of the home country to the subsidiaries, or send the expatriates employees to the home country to take the training programs, or doing the train program in third country, both training specialists and expatriates employees travel to it to perform training or all of these approaches that the nature of the training decide the approach we can use.

In Dawacom global HRM, training method approach is to send the training specialists to the subsidiary to implement the training program for those employees.

Compensation task of global HRM a quires special significance, because it affected by many external considerations related to the country of subsidiary. Some of these considerations include national differences in compensation, county specific standards, minimum wage requirements of that country, working time and holidays ,benefits and severance policies, overtime allowances and restrictions in addition to that income taxes and discretionary expenses. There is an approach to facilitate the employer estimation, this approach called 'balance sheet approach' (Jatin, 2012).

Finally, global HRM concept is becoming biased to treat each county subsidiary with special HRM system according to that county considerations in form lines with the home county HRM value and culture, rather than centralize HRM system .in Dawacom global HRM we tailor special HRM to each county subsidiary.

\section{Methodology}

This project explores the human resource management (HRM) that's the organization needs in order to perform effectively and efficiently. Dawacom HRM is the case study of this project, using qualitative approach methodology, and collecting data via researcher observations, experiences, and practices. This process is discovery oriented, the aim is not to answer a question or solve a problem but to gain deeper understanding.

Qualitative research methodology considered a more descriptive and in-depth approach in collecting and analyzing data. Qualitative research methodology enables researcher to study things in their natural settings, meanings come from researcher experiences, life stories and perception of experiences.

Here we use the phenomenological approach, this approach seeks to describe a phenomenon. As it is exist from the point of view of the person engaged. It is understood that the description is subjective, the approach intents to explore not what is, but what is perceived to be.

The practice of data collection using qualitative method in this project relies on the researcher observations about Dawacom HRM processes, policies, procedures, practices, plans, implementations.

Also the researcher recording field notes from different departments about HRM systems that applied in Dawacom, and from overseeing and supervising Dawacom HR manager and team performing their tasks and practicing their functions.

Many company documents, arrangements, measures, HRIS, workflows were revised and briefed on, such as code of ethics, internal policy, career path, training and developing programs, application form, interviewing forms, compensation sheets in addition to Durra ERP and staff application and social media groups.

\section{Results \& Discussion}

\subsection{Improving Dawacom HRM}

Many actions can be taken to improve Dawacom HRM effectiveness and efficiency, which contribute in maximizing exploitation of human resource. Which represent the main capital asset for Dawacom group.

First of all, increasing the ERP utilization which includes HRIS as a main part and shifting the communication between the employees and HR services toward mobile application that linked to ERP, this step can accelerate HR team response to employees issues, and save time to HR team regarding their jobs.

Human Resource Information Systems HRIS are a means of acquiring, storing, distributing and analyzing information to various managers. HRIS improves traditional processes and enhances strategic decision making ( Chugh, R 2014).With an appropriate HRIS, Human Resources team enable employees to do their own benefits, 
updates changes, thus freeing HR staff for more strategic functions. Additionally, information essential for employee management, career path growth and evolution, knowledge development, and fair treatment is facilitated.

Managers can access the data they need to ethically, legally, and effectively support the performance of their reporting workers. They can perform their reports and enter plans into HRIS to aid with succession (Susan M., 2016).

Human resources staff are responsible for recruiting positions, training workers, providing benefits and handling any objections or disciplinary actions that occur. The day-to-day tasks of managing the workforce can leave little time for long-term planning. Human resources needs to engage in strategic planning in order to commit the company's mission as it relates to the employees. Without annual strategic planning, the firm may find they are not ready to meet future vacations or training requirements.

Strategic planning includes budget analysis, determining and forecasting staffing positions. With any variation, there may be positions that are no longer needed. Human resources would then implement a plan and set a time sheet for a reduction in current positions, severance benefits and career-transition resources for terminated workers ( Mary Nestor,2015).

More action needed to develop a uniquely recruiting, selecting system to fillful deferent positions. These actions include forecasting personnel needs which determine the vacancies that needed to be filled either because of the firm expansion ,or because of bad performance of some employees .perfect job analysis and vacancies expectation decreases problems related to late in fulfillment Different positions . Adding ATS "application Tracking system " helps managers to follow up steps that had been taken to fill full the positions they have in their departments.

In order to develop and improve employees skills and knowledge and actual determining of training needs, we think in designing a training tree for each employee that show to HRM the skills ,knowledge, capabilities of an to employee, also training courses that the employee participate in it and tracking his development. The firms which understand and are aware of the staff behavior and the importance of skills and knowledge implement activities to enhance the skills of their employees (Ernst, et al., 2012). According to (Cekada, 2010) a training requirements assessment is used to determine whether training program is the appropriate solution to a workplace problem. The assessment is a continuous process of collecting data to determine what training needs present in order to improve training that can assess the organization meet its mission and objectives (Brown, 2002).

In an effort to building up loyalty, and belonging to the firm feelings of the employees, a comprehensive loyalty program or project will submitted, through many activities such as social activities (trips, social events participations...etc.), family services (discounts on shops, restaurants... etc. ),provident fund ,car insurance, free stocks .those and related activities enhance employees feelings about their firm.

Enhance participation of HR team with marketing department to strengthen internal marketing that deal with the employees as the corner stone of the firm interest as well as customers. Effective internal marketing empowers workers to absorb the company aspirations, the industry and how to satisfy their customers. Employees with a well understanding of the firm vision will establish long term trusting relationships with customers and committed to their company. When empowered employees say with pottery about the organization, it's value and have prepared lift speeches about the brand (Lyndit, 2010 ).

Optimal organization capabilities exploitation dramatically increases the organization progress and creating a lot of business opportunities that can be extracted from the talent pool from employees. This optimal exploitation could be reached by applying corporate communication project appeared in exploring employees opinions and idea related to corporate decisions rather than their department decisions.

Improving HRM contributes effectively in keeping core competencies of the organization which form the main competitive advantage, especially for Dawacom group.

Organizing, utilizing, and maintenance of a company's workforce is a key function of HRM. This involves preparing an organizational framework that affords maximum usefulness of an enterprise's human capital and posting systems of communication that support the organization operate in a unified pattern.

Significative contributions to business processes are increasingly realized as human resource managers have always contributed to business processes in many respects-by publicizing guidelines for and supervision employee behavior, or ensuring that the company is implementing worker-related regulatory laws. Now, increasing numbers of businesses are combining human resource managers into other business processes as well. 
In the past, human resource managers were dumped in a support role in which their conceptions on cost/benefit vindications and other operational aspects of the business were rarely took in consideration (Mathis et al., 2005).

To go extra mile in improving HRM we seek to engage other departments' managers and supervisors in designing and developing HRM policies and practices which sink finally in improving their departments' performance. Performing many workshops for those managers and supervisors covering HRM issues such as "how to achieve job satisfaction", "linking between corporate and HR strategy"...etc. Researches on HR issues externally and internally broaden the HRM matters that enhances HRM improvement. Career competitiveness research, compensation fairness and motiving research help HRM in amendment current practices in line with market situation.

Designing and performing surveys and questioners periodically with managers or employees or both, can give us an idea about sides that needed to be improved and contribute in new areas that may enhance our HRM. General HR performance survey, career load survey and so on.

Keeping in touch with employees and to build up strong organizational culture \& trust using social media by posts in special staff Facebook group, or Whatsapp group, explaining some events via snapshat. The effective way to build trust in the workplace is to work together. There are no magic simple solutions. Trust cannot be implanted by excessive incentives, interesting company picnics or comfortable working conditions only, it also can be generated through teamwork, fair treatment, and sincerity. Attributes appear to create a positive effect on trust, the manager is open and honest about the daily work business operations.

Another issue in getting high quality job performance from our employees, relies on giving the staff opportunities for their personal growth, responsibility, achievement, recognition, and reward. Once the compensation is established properly, it is important to use other means to boost motivation and improve our employees' output. The basis of all job enhancement efforts is our recognition of workforces' desire to perform well, to conduct responsibility, to accomplish and to succeed. The quality of work life technique is to involve your workers by participating them in the management authority and responsibility.

Suggestions to consider in getting better quality of work life environment include:

Modifying detailed job descriptions with rigorous instructions and specific tasks for the way of performing work, Structured chain of command, supervisors bossing and managers making decisions, Hierarchical routs of communications, vague, irregular job evaluations, careless safety and health conditions to a flexible, assorted work assignment allowing self-control, variety and

challenge. To employee involvement in planning, operating procedure and decision making, to direct, fast channels of communication, to Advanced training, and career path development opportunities, to transparent job performance standards with measures fairly treated, to clean, healthful and safe workplace conditions (Meir Liraz).

Recently, many of these actions take the way to be implemented by HR department.

\subsection{Measuring the HRM performance}

HRM formed a trinity which consists of three ribs: the human resources "employees", the administration system, and the work place environment and culture.

These elements interact with each other to shape the organizational HRM. Whenever these elements or ribs are more consistent and intersecting, then the trinity of HRM will be stronger and have a greater influence in boosting the organizational performance.

Many attributes influence each rib and issue effectiveness. So, we need to control \& measure each attribute in each rib formed the HRM trinity to insure that it work parallel with the organization progress and requirements.

Human Resource Metrics has become necessary for Balanced Scorecards and other measurement systems. The cause is due to the necessity for effective management over human resource capital; i.e. the intellectual asset that drives value. A good place to start is with a set of efficiency ratios to observe how well you are managing human resources. The Society of Human Resource Management has designed ten key human capital measurements:

1. Revenue Factor $=$ Revenue $/$ Total Full Time Employees

2. Voluntary Separation Rate $=$ Voluntary Separations $/$ Headcount

3. Human Capital Value Added $=($ Revenue - Operating Expense - Compensation \& Benefit Cost $) /$ Total Full Time Employees 
4. Human Capital Return on Investment $=($ Revenue - Operating Expenses - Compensation \& Benefit Cost $) /$ Compensation \& Benefit Cost

5. Total Compensation Revenue Ratio $=$ Compensation \& Benefit Cost $/$ Revenue

6. Labor Cost Revenue Ratio $=($ Compensation $\&$ Benefit Cost + Other Personnel Cost $) /$ Revenue

7. Training Investment Factor $=$ Total Training Cost $/$ Headcount

8. Cost per Hire $=($ Advertising + Agency Fees + Recruiter's Salary/Benefits + Relocation + Other Expenses $) /$ Operating Expenses

9. Health Care Costs per Employee $=$ Total Health Care Costs $/$ Total Employees

10. Turnover Costs $=$ Termination Costs + Hiring Costs + Training Costs + Other Costs

It is also important to evaluate your HR metrics against past performance and other organizations (Matt H. Evans, 2015).

Job satisfaction level, absence rate, turnover rate, punishment rate, letter of thanks rate, some metrics attributes related to the employees rib. Cost per hire, time to fill, HR expense factor, career burden, communication level, extra work expense, training courses done, outstanding employees rate, firing rate. Some metrics related to the administration system rib. Diversity rate, Discrimination cases rate, authority \& responsibility matrix. Strategy \& organizational vision absorption rate. Some metrics attribute to the work place environment.

These metrics can be measured by surveys, or filling equations, and by HRIS. and comparing results with the organization profits and strategic aims give up an actual idea about our HRM performance, and show up the attributes needed to improve and work on.

We've provided some primary and standard metrics that we note many firms using, to get started measuring HR:

\begin{tabular}{|c|c|}
\hline Metric & Formula \\
\hline Absence rate & \# days absent in month $\div$ (average $\#$ of employees during a month $\mathrm{x} \#$ of workdays) \\
\hline Benefit or program costs per employee & total cost of employee benefit/program $\div$ total \# of employees \\
\hline Benefits as a percent of salary & annual benefits cost $\div$ annual salary \\
\hline $\begin{array}{l}\text { Compensation as a percent of total } \\
\text { compensation }\end{array}$ & annual salary $\div$ total compensation (salary + benefits + additional compensation) \\
\hline Compensation or benefit revenue ratio & compensation or benefit cost $\div$ revenue \\
\hline Cost per hire & recruitment costs $\div$ (compensation cost + benefits cost $)$ \\
\hline Engagement or satisfaction rating & percent of employees engaged or satisfied overall or with a given aspect of the workplace \\
\hline $\begin{array}{l}\text { Percent of performance goals met or } \\
\text { exceeded }\end{array}$ & $\#$ of performance goals met or exceeded $\div$ total $\#$ of performance goals \\
\hline Percent receiving performance rating & $\begin{array}{l}\text { \# of employees rated under a given score or rating on their performance evaluation } \div \text { total \# of } \\
\text { employees }\end{array}$ \\
\hline Revenue per employee & revenue $\div$ total $\#$ of employees \\
\hline Return on investment (ROI) & (total benefit - total costs) $\times 100$ \\
\hline Time to fill (average) & total days taken to fill a job $\div$ number hired \\
\hline Training/development hours & sum of total training hours $\div$ total $\#$ of employees \\
\hline
\end{tabular}


Tenure

Turnover (annual)

Turnover costs

Utilization percent average \# of years of service at the organization across all employees

\# of employees exiting the job during 12 month period $\div$ average actual \# of employees during the same period

total costs of separation + vacancy + replacement + training

total number of employees utilizing a program/service/benefit $\div$ total number of employees eligible to utilize a program/service/benefit

Keep in mind that this is a sample of the many metrics we can use to evaluate the effectiveness of our HR performance (ERC, 2014).

\section{Conclusion}

Throughout the project we intended to analysis good HRM system. The Dawacom needs in order to perform well, and what are the dimensions specific to this field of activity. This project was oriented towards exploring current Dawacom HRM and comparing it to the right standards.

Our project reveals the fact the personnel who work or are interested in their firm, they are treated fairly, be cared about their safety and health, can help the company they work for to obtain human capital that can be converted to financial capital and thus increase the competitiveness of the firm in the market.

A conclusion that can draw, after sealing through this project is that we will have to call for actions of the most diverse and attractive. So that the chances of success will be higher .In addition, it is clear that the firm need to focus on the relations it has with it employees, it has to encourage honesty and explain, its values to all of them and make sure that they accept them and act accordingly.

Therefore if a firm wants effectiveness, performance, and increased productivity.it has to take inconsideration the recruiting, selections, orienting, training, appraising, rewarding, communicating, its employees possess and to create an environment that raided vitality.

\section{References}

ACIB (Australian Centre for International Business). (2000). The International Business Case for Diversity Management, Program for The Practice of Diversity Management, Department of Immigration and Multicultural Affairs in Cooperation with the Australian Center for International Business.

Brown, J. (2002). Training Needs Assessment: A must for Developing an Effective Training Program. Public Personnel Management, 31(4), pp. 569-578.

Burke (2008). Clinical Pharmacist Competencies. Pharmacotherapy: The Journal of Human Pharmacology and Drug Therapy, 28(6), 806-815.

Cassel, C. (1996).A Fatal Attraction? Strategic HRM and the Business Case for Women's Progression. Personnel Review, 25(5), 51-66.

Cekada, T. (2010). Traning Needs Assessment: Understanding what Employees need to know. Professional Safety, 28-33.

Chad, H. (2013). Articles in Building an Ethical Workplace. Retrieved from http://www.wheniwork.com/building-an-ethical-workplace

Chugh, R. (2014). Role of Human Resource Information Systems in an Educational Organisation. Journal of Advanced Management Science, 2(2), 149-153. Retrieved from http://www.joams.com/index.php? $\mathrm{m}=$ content\&c=index \&a=show\&catid=37\&id=132

Clavier, C. (2013). Academic Performance of First Year Students at a College of Pharmacy in East Tennessee: Models for Prediction. Johnson City: East Tannessee State University.

Collings, D. G., \& Wood, G. (2009). Human resource management: A critical approach. In D. G. Collings \& G. Wood (Eds.), Human resource management: A critical approach (pp. 1-16). London: Routledge.

Cox, T., \& Blake, S. (1991). Managing Cultural Diversity: Implications for organizational Competitiveness. Academy of Management Executive, 5(3), 45-56. 
ERC. (2014). 20 Common HR Metrics and their Formulas. Retrieved from https://www.yourerc.com/blog/post/20-Common-HR-Metrics-and-their-Formulas.aspx

Ernst, E. (2012). Recommendations for Training and Certification for Pharmacists Practicing, Mentoring, and Educating in Infectious Diseases Pharmacotherapy. The Journal of Human Pharmacology and Drug Therapy, 29(4), 482-488.

Government of Australia. (2016). Workplace health \& safety. Retrieved from https://www.business.gov.au/info/run/workplace-health-and-safety.

Gray, D. (2005). Human resource management Ethics, Justice, and Fair Treatment in HR Management, prentice hall.

Gray, D. (2012). Human resource management.

Gubman, E. L. (1996). The Gauntlet is Down. Journal of Business Strategy. Retrieved from www.inc.com/encyclopedia/human-resource-management.html.

Gupta, K. (2011). A Practical Guide to needs Assessment (2nd ed.). U.S.A.: John Wiley \& Sons.

Jackie, L. (2016). The Ethics of Justice \& Fair Treatment in HR Management, Retrieved from yourbusiness.azcentral.com/ethics-justice-fair-treatment-hr-management-28144.html.

Jatin, V. (2012). Global human resource management, Human Resource Management in International Business. Retrieved from www.slideshare.net/jatinmaims/global-human-resource-management.

Jie, S., Ashok, C., Brian, D., \& Manjit, M. (2009). Managing diversity through human resource management: An international perspective and conceptual framework a School of Management, University of South Australia. The International Journal of Human Resource Management, 20(2), 235-251.

Johnason, P. (2009). HRM in changing organizational contexts. In D. G. Collings \& G. Wood (Eds.), Human resource management: A critical approach (pp. 19-37). London: Routledge.

Kandola, R. (1995). Managing Diversity: New Broom or Old Hat?

Kossek, E. E., Lobel, S. A., \& Brown, A. J. (2005). Human Resource Strategies to Manage Workforce Diversity. Thousand Oaks.

Lyndit, T. (2010). Importance-of-internal-marketing. $\quad$ Retrieved from www.lyndit.com/2010/07/importance-of-internal-marketing.

Malyan C. S. (2014). Managing Global Human Resource Administration. Retrieved from http://www.slideshare.net/Nenemane/managing-global-human-resource-management

Mary, N. H. (2015). How to Forecast Future HR Needs.

Mathis, Robert L., and John, H. Jackson, 2005. Human Resource Management. Thomson South- western.

Matt, H. E. (2015). Metrics for human resource management. Retrieved from http://www.exinfm.com/board/metrics_for_hr_management.htm

McLeod, L., \& Cox. (1996). Ethnic Diversity and Creativity in Small Group. Small Group Research, 27(2), 248-264.

Mondy, R. W., \& Judy, B. (2014). Human resource management (13th ed.). Harlow, England: Pearson Education Limited.

Robinson, M. (2012). What is Job Analysis? (PDF). Institute of Work Psychology.

Rumel (2012). Safety and Health ,Managing Human Resources. Retrieved from http://www.slideshare.net/rumel009/employee-safety-and-health-14803872

Sagar, J. (2014). Job analysis, job description and job specification. Founder \& CEO @ Intos HR Solutions LLP.

Schulz, B. (2008). The Importance of Soft Skills: Education beyond academic knowledge. Journal of Language and Communication, 146-157.

Susan M. H. (2016). Human Resources Information System (HRIS) Definition and Description.

Susan, M. H. (2016). Beyond Hiring and Firing: What is HR Management?

Wilson, M. (2007). A history of job analysis. In L. Koppes, Historical perspectives in industrial and organizational psychology. Mahwah, NJ: Lawrence Erlbaum Associates. 


\section{Copyrights}

Copyright for this article is retained by the author(s), with first publication rights granted to the journal.

This is an open-access article distributed under the terms and conditions of the Creative Commons Attribution license (http://creativecommons.org/licenses/by/4.0/). 